\title{
Surface Strengthening of High Speed Steel by PCVD Combined Nitriding-Coating
}

\author{
XU Yuezeng ${ }^{1, a}$, JIANG Fan ${ }^{1, b}$ \\ ${ }^{1}$ Zhejiang tongji vocational college of science and technology, Hangzhou 311231, China \\ a yzxu9@126.com, ${ }^{\text {b }}$ fanfan_0099@163.com
}

\begin{abstract}
Keywords: Plasma chemical vapor deposition(PCVD), Titanium nitride, Composite depositing, Cutting tools, cutting property.
\end{abstract}

\begin{abstract}
To study the effects of PCVD combined nitriding coating processing on cutting performance of high speed steel tool, the PCVD was performed on W6Mo5Cr4VZ (MZ) steel tools to get surface strengthening, tool surface micro-hardness before and after PCVD process was studied, wear property and bonding force both before and after PCVD was analyzed, observed the PCVD impacts on antioxidant property. SEM was used to analyze PCVD area and substrate of the tools. The results show that (MZ) high speed steel tool micro-hardness improved obviously, wear property improves as well. The good antioxidant ability in the PCVD layer provides great cutting property to tools, SEM found that sample treated by PCVD have smooth fracture morphology, in which substrate and PCVD layer is clear.
\end{abstract}

\section{Introduction}

With rapidly development in fields of aerospace and machinery industry, application of high hardness materials and difficult to machine materials are more and more wildly. Tool selection becomes trial when high hardness alloy materials are machined. Requirements of high speed tool are more and more rigid when cutting technology is marked by efficient CNC machine center. Especially, with development of turning instead of grinding technology, high hardness materials should be cut by tools directly, which make the work conditions of tool extremely worse.

In the fields of tool surface PCVD, there are several types of machining method to get TiN coated tools with the same physical properties and the different efficiency and practicability.For example, in the technology of CVD, the coating of cutting tools are bound with tools firmly, which make cutting tools worn less and cheaper. However, deposition temperature is as high as $1170-1370 \mathrm{~K}$ which limits application range of machining. Cutting tools made by CVD technology which emerged in 70's has property of good quality of tool coating and low deposition temperature. What make CVD technology cannot replicate on a large scale is high cost of investment and expensive devices with difficult maintenance and operation. Nowadays, researchers in domestic and abroad have already studied on surface strengthening with VCD combined nitriding-coating technology. It can significantly improve bind force of coating and matrix, hardness of tool surface, friction wear and comprehensive mechanical properties of coating. PCVD combined nitriding coating have several advantages as follow: low deposition temperature, little deformation, high accuracy, rapid deposition speed, low investment, simple operation and maintenance and so on.

Although regular patterns were concluded by researchers which target on tool surface strengthening of PCVD, research on cutting tool made by W6Mo5Cr4VZ (MZ) high speed steel as object to improve machining performance are few report. In the paper, cutting tool made by (MZ) high speed steel is researched as object of study and operation of PCVD combined with nitriding coating is carried out. The influences of friction wear and machining performance are revealed. Meanwhile, method of tool surface strengthening by PCVD has laid a firm basis for further research.

\section{Test method}

Devices of PCVD are used to surface treatment combined with nitriding coating of cutting tools 
of (MZ) high speed steel and system theory is shown in Figure 1. Process continuously performance as nitriding first and then plating.

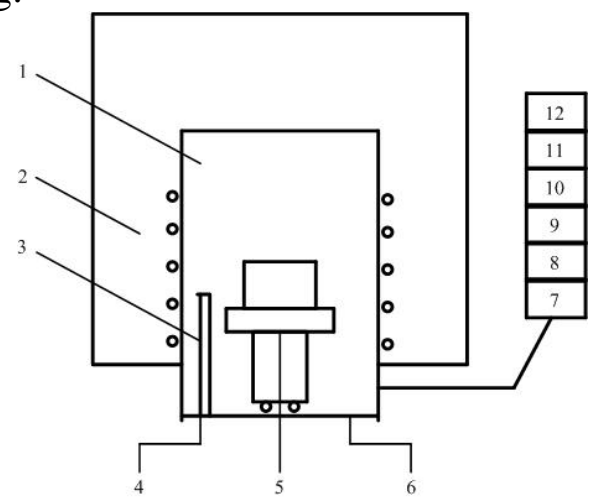

1. Vacuum chamber, 2. Heating furnace, 3. Thermocouple, 4. Temperature controlling system, 5.

Electrical source, 6. Pump, 7. Ar, 8. N2, 9. H2, 10. CH4, 11. TiCl4, 12. SiCl4, 13. Work piece.

Figure 1 PCVD System Working Graph

Process of PCVD combined with nitriding coating is: plasma nitriding $\rightarrow$ vapor deposition. In process of plasma nitriding, mixed gas of $\mathrm{N}_{2}$ and $\mathrm{H}_{2}$ is injected into vacuum chamber and then open electrical source. When negative high voltage is exerted on cutting tools and plasma field will occur. Plasma nitriding begin when reach certain temperature and vapor deposition begin when nitriding coating become certain thickness.

Vickers hardness is used to detected the micro-hardness of tool surface compared with PCVD and not. Test load force is $0.5 \mathrm{~N}$. tools binding force connected with ( $\mathrm{Ti}, \mathrm{Si}$ ) N plating and matrix is detected by Rockwell hardness. Test load force is 1.5[N]. Section property of tools plating is observed by scanning electron microscope and Ti/Si proportion is obtained by XRD technology. Samples of PCVD and not are tested in friction wear test machine which type is UMT-2. Differences of wear resistance are judged by weight loss with rotation speed at $500 \mathrm{r} / \mathrm{min}$ and sample friction wear are measured by precision balance.

\section{Results and discussions}

Micro-hardness. Hardness values of (Ti, Si) N coatings in different Ti/Si ratio are shown in Table 1. What can be seen is the hardness value of tool surface without treatment is $1700 \mathrm{HV}_{0.05}$. According to different $\mathrm{Ti} / \mathrm{Si}$ ratios, hardness values of $(\mathrm{Ti}, \mathrm{Si}) \mathrm{N}$ coatings range from $2300 \mathrm{HV}_{0.05}$ to $2800 \mathrm{HV}_{0.05}$. Compared with tool surface without treatment, hardness of tool surface with treatment gets more improved. Among all, hardness value of tool surface with (Ti, Si) N+TiN coating increased most is $3600 \mathrm{HV}_{0.05}$. Hardness of tool surface with PCVD combined with nitriding coating is much higher than tool surface without treatment and tool surface with single $(\mathrm{Ti}, \mathrm{Si}) \mathrm{N}$ coating.

Table 1 Micro-hardness of coating layer under different treatment conditions

\begin{tabular}{ccccccc}
\hline Ti/Si ratio & 0 & $0.90 / 0.10$ & $0.70 / 0.30$ & $0.30 / 0.70$ & $0.08 / 0.92$ & combination \\
\hline $\mathrm{HV}_{0.05}$ & 1700 & 2300 & 2480 & 2650 & 2800 & 3600 \\
\hline
\end{tabular}

Wear performance. $5 \mathrm{~mm}$ disk simples are made by (MZ) high speed steel with PCVD treatment or not. GCr15 with Ra $<0.01 \mathrm{~mm}$ roughness is selected as friction coupling. In test conditions at room temperature and oil lubricant, friction coefficient is obtained by friction torque which is recorded during test divided by load force. Samples with PCVD treatment before and after test are measured by electronic balance and results are shown in Table2. According to calculation, wear loss of (MZ) high speed steel with PCVD treatment is 30\% compared to steel without treatment. It can be seen friction wear resistant of (MZ) high speed steel with PCVD treatment significantly improves. 
Table 2 Weight loss of both PCVD and untreated samples

\begin{tabular}{cccc}
\hline type & Weight before test[g] & Weight after test[g] & Wear loss[g] \\
\hline Not treatment & 60.3216 & 60.3104 & 0.0112 \\
PCVD treatment & 61.1720 & 61.1707 & 0.0013 \\
\hline
\end{tabular}

Relation between friction coefficient and time is shown in Figure 2. it can be seen that friction coefficient of samples with PCVD combined with nitriding coating is always lower than samples without treatment. In beginning of test, protection oil film is not shaped on surface of (MZ) high speed steel by lubricants. Dry friction is generated between friction couplings and friction coefficient is large. After oil film shaping, friction coefficient decrease and become smooth. Near the end of test, because of wear on surface of tool samples, it is a small spike in friction coefficient.

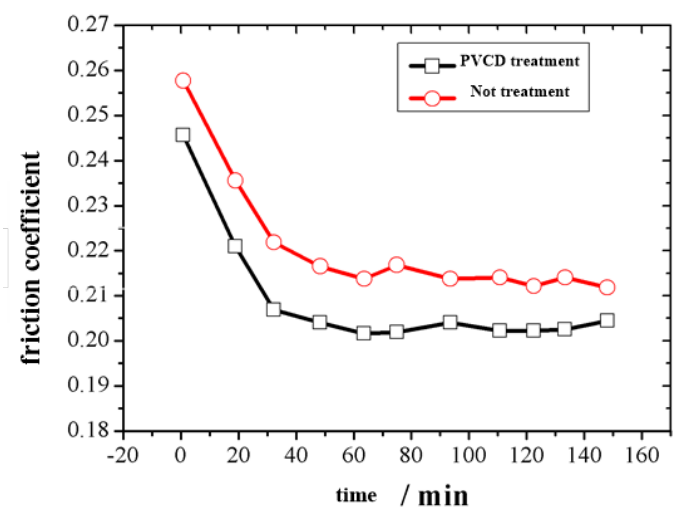

Figure 2 Friction coefficients before and after wear of untreated and PCVD samples Table 3 Micro-hardness of coatings after heating

\begin{tabular}{ccccccc}
\hline $\mathrm{T}\left[{ }^{\circ} \mathrm{C}\right]$ & $\mathrm{TiN}$ & $0.90 / 0.10$ & $0.70 / 0.30$ & $0.30 / 0.70$ & $0.08 / 0.92$ & combination \\
\hline 30 & 1700 & 2300 & 2480 & 2650 & 2800 & 3600 \\
\hline 550 & 1200 & 2150 & 2240 & 2430 & 2620 & 3200 \\
\hline 650 & Failure & 1800 & 2000 & 2200 & 2430 & 3050 \\
\hline 750 & Failure & Failure & 1850 & 2120 & 2200 & 2920 \\
\hline
\end{tabular}

Oxidation resistance. (MZ) high speed steel with different ratio of Ti/Si are heated in 1 hour to take oxidation resistance test in steel with treatment or not. Test results are shown in Table3. Failure state is defined as state which hardness of coating is less than $1000 \mathrm{HV}$. Hardness values are marked when it is not in failure state. In Table3, oxidation resistance of coatings with PCVD treatment is obviously better than TiN coatings. Oxidation resistance of coating is also influenced by ratio of $\mathrm{Ti} / \mathrm{Si}$. When content of Si increase, oxidation resistance of coating improves.

Scanning electron microscope analysis. Figure 3 shows section properties of (MZ) high speed steel with treatment or not after machining test. Cutting material is $40 \mathrm{Cr}$, cutting parameters are: main shaft speed $V_{c}=400[\mathrm{~m} / \mathrm{min}]$, back engagement of the cutting edge $a_{p}=2[\mathrm{~mm}]$, feeding velocity $\mathrm{f}_{\mathrm{z}}=0.2[\mathrm{~mm} / \mathrm{r}]$. Figure 3 (a) shows section properties without treatment and Fig3 (b) shows section properties with treatment. Compared Figure 3 (a) with Figure 3 (b), wear of cutting face is serious in sample without treatment and section of tool is rough. While wear of cutting face is slight in sample with treatment and section of tool is smooth. It sufficiently proves that friction wear resistant of (MZ) high speed steel with PCVD treatment significantly improves. 


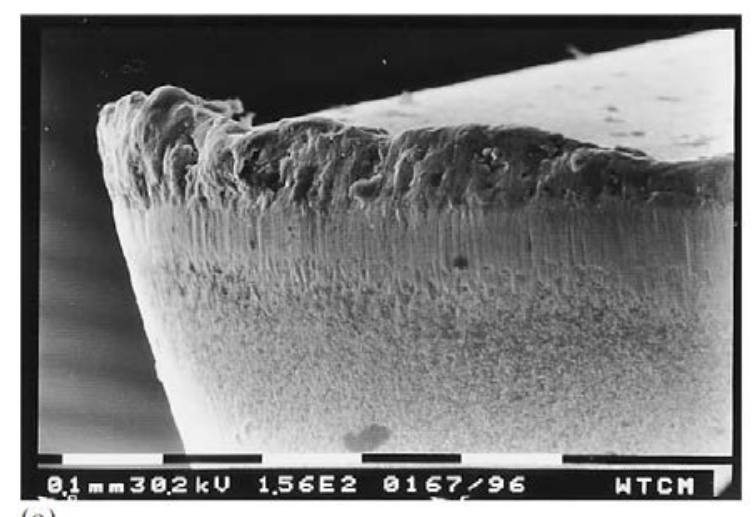

(a)

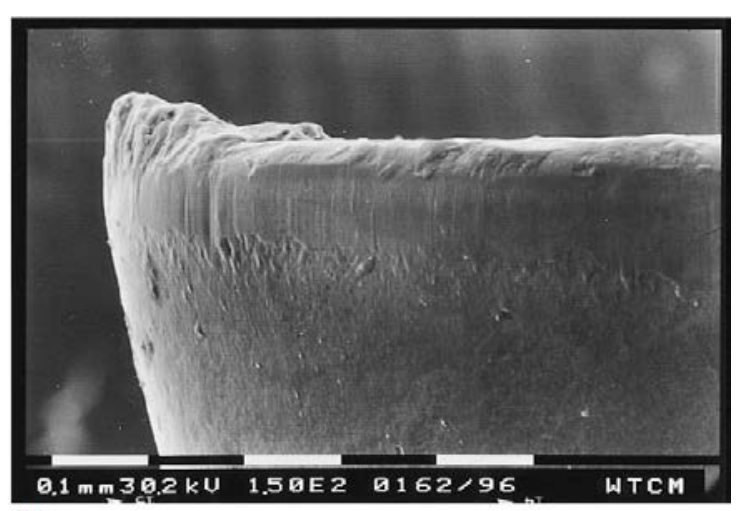

(b)

Figure 3 Morphology different conditions (a) untreated; (b) PCVD combined treatment

\section{Summary}

By PCVD combined nitriding coating treatment carried out in W6Mo5Cr4VZ (MZ) high speed steel, it can be summarized as follows:

(1) Micro-hardness of tool coating is obviously improved by PCVD combined nitriding coating technology. Wear resistance is improve by hardness.

(2) It is important for coating to change ratio of Ti/Si. When content of Si increase, combination force of coating and matrix increase, which improves oxidation resistance of coating.

(3) Machining test shows that wear of cutting face is slight in sample with treatment and section of tool is smooth. It sufficiently proves that friction wear resistant of (MZ) high speed steel with PCVD treatment significantly improves.

\section{Reference}

[1] Long-Zhongji, Tang-Qihuan. Application of PCVD Technology (surface technology, 1992).

[2] Li-Jun, Ouyang Jun, Chen Dakai. The Influence of PCVD Coating to Structural Steel in Different Media (Journal of Wuhan University of Science and Technology, 1997).

[3] Chen Zhengwen,Shang Hongfei,Xu Jianhua et al. Study on Performance of Cutting Tool with PCVD Coating Based on Cutting Force (Tool Engineering, 2012).

[4] Chang Xuhua Zhang Yongbo. Analysis of Suspension Spring Fracture Cause as Per Pressing (Steel Wire Products, 2006).

[5] K. Vandierendonck, M. Van Stappen. Study of the Performance of PVD and PCVD Coated Cermets for Different Cutting Applications (Surface and Coatings Technology, 1997) . 